\title{
C-reactive protein as a biochemical marker for idiopathic preterm delivery
}

\begin{abstract}
Background and objective: Estimation of $\mathrm{C}$-reactive protein is a simple method and could be helpful in detecting cases at risk for pre-term delivery. In this study we examined the association of maternal C-reactive protein in second trimester with risk of occurrence of preterm delivery later on.

Methods: A prospective case-cohort study was conducted between June 2011 and July 2012 at Maternity Teaching Hospital Iraq- Erbil. The sample size was 205 women at gestational age of $20^{+0}$ weeks to $26^{+6}$ weeks and after exclusion of all risk factors for preterm delivery. High-sensitivity C-reactive protein assays were performed on serum samples.
\end{abstract}

Results: Median concentration of C-reactive protein was $4.7 \mathrm{mg} / \mathrm{liter}$. No significant association was found between high level of C-reactive protein and occurrence of preterm delivery $(P=0.78)$.

Conclusion: Measurement of C-reactive protein in second trimester cannot be used as an indicator for pre-term delivery.

Keywords: C-reactive protein, premature uterine contractions, premature delivery, pre-term delivery.

\section{Introduction}

Preterm births occur in approximately $12 \%$ of pregnancies and it is the leading cause of neonatal mortality in the United States. ${ }^{1,2}$ In addition to the high perinatal mortality, the risk of later neurodevelopmental impairment, disability and handicap are especially significant within the 24-26 weeks gestational age window. ${ }^{3}$ Up to $40 \%$ of survivors born before 26 weeks gestation were found to have a head circumference below $3^{\text {rd }}$ centile at two years of age after which little catch up growth is possible. ${ }^{4}$ Successful reduction of perinatal mortality and morbidity associated with prematurity may require implementation of programs for accurate identification of pregnant women at risk. In fact, recent evidence suggests that early identification of at-risk pregnancies with timely referral for sub specialized obstetrical care may decrease morbidities of extreme prematurity $(<32 \text { weeks })^{5}$
A short or partially dilated cervix may allow bacteria to ascend into the lower pole of the uterus where inflammatory response will be triggered. This then leads to cervical ripening and shortening, decreasing the ability of the cervix to act as a mechanical or microbiological barrier and, ultimately leads to the development of either localized or generalized chorio-amnionitis and leads to preterm delivery. ${ }^{6}$ However, it's also possible that with a high number of virulent pathogens in the vagina, bacteria may gain access to the lower pole of the uterus through a normally functioning cervix and then ripening of cervix will happen. Bacteria may also gain access to the amniotic cavity through hematogenous spread or by introduction at the time of invasive procedures. ${ }^{6}$ Hematogenous spread can also be from oral bacteria although studies of intensive dental hygiene in pregnancy have not shown to reduce the risk. ${ }^{7,8}$ The earliest births carry

* Maternity Teaching Hospital, Erbil, Iraq.

** Department of obstetrics and gynecology, college of medicine, Hawler Medical University, Erbil, Iraq. 
the highest risk of an infection as etiology. ${ }^{9}$ Although the patho-physiology of preterm delivery remains unknown, importantly, some investigators have indicated that infections are major causes of preterm deliveries (PTD), responsible for about $30 \%-50 \%$ of all cases. ${ }^{10,11}$ Moreover there is increasing evidence, which suggests that other infectious processes occurring elsewhere in the body may contribute to preterm delivery. ${ }^{12,13}$ C-reactive protein (CRP) is a protein found in the blood, the levels of which rise in response to inflammation. ${ }^{14}$ It is an acute-phase reactant protein synthesized primarily by liver cells in response to the proinflammatory cytokines including interleukin -6 and TNF- $\alpha{ }^{15,16}$ CRP concentrations in peripheral circulation are also known to be associated with high body mass index (BMI) and other markers of adiposity. ${ }^{17,18}$ On the same basis ladies with BMI $\geq 30$ were excluded from the study. Elevation of C-reactive protein in maternal peripheral circulation is associated with the presence of intrauterine infection. ${ }^{19,20}$ Endothelial dysfunction has been postulated to be part of an exaggerated maternal inflammatory response to pregnancy. ${ }^{21}$ In addition, cross -sectional analyses indicate that CRP is strongly correlated with markers of endothelial activation and dysfunction. ${ }^{22}$ Collectively, these findings, suggest that C-reactive protein, a marker of systemic inflammation, may be involved in the pathogenesis of preterm delivery. Hvilsom et al in $2002^{23}$ were among the first group of investigators to report that elevated concentrations of CRP in maternal serum during early pregnancy ( $\geq 85$ th percentile vs. $<85$ th percentile) were associated with a two-fold increased risk of preterm delivery $(\mathrm{OR}=2.0,95 \% \mathrm{Cl}:$ 1.2-3.5). Some others have corroborated this early finding, ${ }^{24,25}$ though not all investigators. ${ }^{26}$ The aim of this study was to assess the association of CRP, a marker of inflammation, with preterm delivery, to examine the reliability of CRP in maternal serum as a marker of premature birth among pregnant women who had no of the known risks for premature birth and to determine critical value of CRP in pregnancies that ended up with a premature birth.

\section{Methods}

The population for the present analysis was drawn from the attendants of antenatal care clinic at Maternity Teaching Hospital in Erbil/Iraq in the period from June 2011 to July 2012. Women eligible for inclusion were those who started antenatal care prior to 20 weeks gestation, were $\geq 18$ years old, BMI $<30$, could speak Kurdish or Arabic, at gestational age between $20+^{\circ}$ and $26+{ }^{6}$, planned to carry the pregnancy to term, and to deliver at study hospital. Both nulliparous and multiparous women were approached and enrolled. They were asked to take part in an hour-long interview in which trained personnel used a structured questionnaire to get information about maternal sociodemographic characters, maternal age, occupation and reproductive and medical history. Participants also provided nonfasting blood sample for estimation of $\mathrm{CRP}$, high vaginal swab, mid stream urine for analysis and culture and sensitivity, and trans-vaginal sonography for measurement of cervical length. The BMI was taken from booking records. Pregnancy outcome information was ascertained by a direct contact with the participants. During the study period, 208 eligible women were approached, and all gave a well-informed verbal consent. Three women were lost from follow up and were excluded from the analysis. Any woman at risk for pre-term birth such as having a history of pre-term birth, cervical incompetence, urinary tract infection (proved by urine test), bacterial vaginosis, diabetes (gestational or non gestational), hypertension, multiple gestations, poly-hydramnios, uterine congenial abnormality, placenta previa, and $\mathrm{BMI} \geq 30$ was excluded from the study. Gestational age was based on the last menstrual period (LMP) and confirmed by ultrasound examination, 
conducted prior to 20 weeks gestation. If both last menstrual period and ultrasound dating were available and the difference between ultrasound and LMP exceeded one week then the ultrasound dating was used to assign gestational age. We categorized preterm delivery cases according to gestational age. Serum CRP levels were measured by quantitative highly sensitive immunoassay test (the i-CHROMATM CRP Test along with i-CHROMATM Reader). It is a fluorescence immunoassay that measures CRP in serum, plasma, and whole blood. A single technician and a single laboratory specialist did all the tests by ELISA method. The lab staff members were blinded for the blood samples. Maternal non-fasting blood samples were collected at gestational age 21.8 (The mean gestational age at time of sampling) in $10 \mathrm{ml}$ test tube without anticoagulant and allowed to clot. The serum was then removed from the sample as soon as possible to avoid hemolysis. Samples were kept frozen until tested. A levels $\geq 10 \mathrm{mg} / \mathrm{l}$ was considered being high. Patients were followed up until delivery and the gestational age at the time of delivery was noted.

Statistical analysis and ethical consideration: The distribution of maternal socio-demographic characteristics, medical and reproductive histories according to preterm and term delivery status was examined. To estimate the relative association between varying concentrations of CRP and risk of preterm delivery, the data was analyzed using the statistical package for the social sciences (version 18). Student's $t$ test was used to compare between means and Chi square test of association was used to compare between proportions. $P$ value of $\leq 0.05$ was considered statistically significant. The scientific and ethical committee of the Council of Arab Council for Medical Specialties approved the study.

\section{Results}

Approximately $11.7 \%$ of the women (24 of 205) in this study delivered preterm. Among preterm deliveries, $95.8 \%$ were preceded by spontaneous premature uterine contractions. Approximately $4.17 \%$ were classified as medically indicated preterm delivery with no records for pre-labor preterm rupture of membrane (PPROM) as shown in Table 1. Table 2 represents the results according to the CRP values in which $<10$ is normal and $\geq 10$ is abnormal depending on the laboratory standard ranges. We found that 167 of the cases had normal CRP values $(<10) ; 19(11.4 \%)$ ended preterm and $148(88.6 \%)$ delivered at term. Of the 38 cases with abnormal value $(\geq 10)$, $5(13.2 \%)$ pregnancies ended preterm and $33(86.8 \%)$ delivered at term. The total preterm deliveries were $24(11.7 \%)$ and the total term deliveries were $181(88.3 \%)$. There was no statistically significant relation between high CRP value in second trimester of pregnancy and preterm delivery $(P=0.781)$.

Table 1: The total preterm deliveries and the pathophysiological classification.

\begin{tabular}{|c|c|c|c|c|c|c|}
\hline \multirow{2}{*}{$\begin{array}{l}\text { Total pre-term deliveries } \\
\text { Total no. }\end{array}$} & \multicolumn{2}{|c|}{ Spontaneous Pre-term deliveries } & \multicolumn{2}{|c|}{ Medically indicated pre-term deliveries } & \multicolumn{2}{|c|}{ PPROM } \\
\hline & No. & $\%$ & No. & $\%$ & No. & $\%$ \\
\hline 24 & 23 & 95.83 & 1 & 4.17 & 0 & 0 \\
\hline
\end{tabular}

Table 2: CRP level in relation with pre-term delivery.

\begin{tabular}{|c|c|c|c|c|c|c|c|}
\hline \multirow[t]{3}{*}{ CRP mg/l } & \multicolumn{4}{|c|}{ Delivery } & \multicolumn{2}{|c|}{ Total } & \multirow[t]{3}{*}{$P$ value } \\
\hline & \multicolumn{2}{|c|}{ Pre-term } & \multicolumn{2}{|c|}{ Term } & \multirow[b]{2}{*}{ No. } & \multirow[b]{2}{*}{$\%$} & \\
\hline & No. & $\%$ & No. & $\%$ & & & \\
\hline$<10$ & 19 & 11.4 & 148 & 88.6 & 167 & & \multirow{3}{*}{0.781} \\
\hline$\geq 10$ & 5 & 13.2 & 33 & 86.8 & 38 & & \\
\hline Total & 24 & 11.7 & 181 & 88.3 & 205 & & \\
\hline
\end{tabular}


Table 3 shows the relation between the CRP values and the different variables in the study, which shows no significant relation. Both primi-gravida and multigravid was were included in the study and there was no significant relation between parity and CRP level as shown in Table 4. Table 5 shows the relation between very high level of CRP and preterm labor. In this table we classified our results into three CRP values. We found that preterm deliveries were $19(11.4 \%)$ when CRP was $<10$, and became $2(10 \%)$ when CRP was between 10 and 19 and then 3 (16.7\%) when CRP was $\geq 20$. The percentage of preterm delivery was highest in very high CRP value (i.e. $\geq 20$ ) but this was not statistically significant.

Table 3: The relation between CRP and variables.

\begin{tabular}{|c|c|c|c|c|c|}
\hline \multirow[t]{2}{*}{ CRP level mg/l } & \multicolumn{2}{|c|}{$\geq 10(\mathrm{~N}=38)$} & \multicolumn{2}{|c|}{$<10(N=167)$} & \multirow{2}{*}{$P$ value } \\
\hline & Mean & SD & Mean & SD & \\
\hline Age in years & 28.37 & 5.70 & 27.81 & 6.46 & 0.63 \\
\hline Cervical length in $\mathrm{mm}$ & 33.62 & 7.10 & 33.97 & 5.30 & 0.73 \\
\hline Number of previous abortions & 0.18 & 0.61 & 0.29 & 0.61 & 0.32 \\
\hline
\end{tabular}

Table 4: The relation between parity and CRP value.

\begin{tabular}{|c|c|c|c|c|c|}
\hline \multirow{2}{*}{$\begin{array}{l}\text { CRP mg/l } \\
\text { Primigravida }\end{array}$} & \multicolumn{2}{|c|}{$\begin{array}{l}\geq 10 \\
(N=38)\end{array}$} & \multicolumn{2}{|c|}{$\begin{array}{l}<10 \\
(\mathrm{~N}=167)\end{array}$} & \multirow{2}{*}{$\begin{array}{l}\begin{array}{l}\text { Total } \\
(\mathrm{N}=205)\end{array} \\
79\end{array}$} \\
\hline & 16 & $42.1 \%$ & 63 & $37.7 \%$ & \\
\hline Multigravida & 22 & $57.9 \%$ & 104 & $62.3 \%$ & 126 \\
\hline$P$ value & \multicolumn{5}{|c|}{0.721} \\
\hline
\end{tabular}

Table 5: Pregnancy outcome in relation with the level of CRP.

\begin{tabular}{|c|c|c|c|c|c|c|c|}
\hline \multirow{3}{*}{ CRP mg/l } & \multicolumn{4}{|c|}{ Pregnancy outcome } & \multirow{2}{*}{\multicolumn{2}{|c|}{ Total }} & \multirow{3}{*}{$P$ value } \\
\hline & \multicolumn{2}{|c|}{ Term } & \multicolumn{2}{|c|}{ Pre-term } & & & \\
\hline & No. & $\%$ & No. & $\%$ & No. & $\%$ & \\
\hline$<10$ & 148 & 88.6 & 19 & 11.4 & 167 & 100 & \\
\hline $10-19$ & 18 & 90 & 2 & 10 & 20 & 100 & 0.499 \\
\hline$\geq 20$ & 15 & 83.3 & 3 & 16.7 & 18 & 100 & \\
\hline Total & 181 & 88.3 & 24 & 11.7 & 205 & 100 & \\
\hline
\end{tabular}




\section{Discussion}

In the current study we found that there was no association between midpregnancy maternal serum CRP and preterm delivery as the mean and the median of CRP in preterm deliveries (8.09 and $6.59 \mathrm{mg} / \mathrm{l}$, respectively) did not differ significantly from the mean and median serum CRP in term deliveries (7.05 and $4.64 \mathrm{mg} / \mathrm{l}$, respectively). This finding was similar to Ghezzi $\mathrm{F}$ et $\mathrm{al}^{27}$ in which no relationship was found between maternal blood C-reactive protein concentration and preterm delivery. Another study done by Borna et $\mathrm{al}^{28}$ showed no correlation between amniotic fluid high sensitive-CRP concentrations with preterm delivery. Ozer et $\mathrm{al}^{29}$ did not find any difference with respect to mean high sensitive-CRP levels between term and preterm deliveries and high sensitive-CRP levels higher than 5 $\mathrm{mg} / \mathrm{l}\left(75^{\text {th }}\right.$ percentile) had sensitivity of $30 \%$, specificity of $87 \%$ in the prediction of spontaneous preterm delivery at $<37$ weeks. While Pitiphat et al ${ }^{24}$ enrolled 2,670 consenting women between April $22^{\text {nd }}$, 1999 , and July $31^{\text {st }}, 2002$, of whom 329 subsequently became ineligible because of multiple gestation ( $n=19)$, because obstetric care was transferred to a non study site $(n=115)$, or because the women were no longer pregnant $(n=195)$. Of the 2,341 remaining participants, 195 (8\%) withdrew and 18 (<1 percent) were lost to follow-up. For this analysis, of the 2,128 participants who delivered a live infant, they included the 2,088 women who also provided blood samples in early pregnancy. They found no significant association between quartiles of CRP and preterm delivery. They also found that very high levels of maternal plasma CRP in early pregnancy were associated with increased risk of preterm delivery. In this study we found that the percentage of preterm delivery in very high level of CRP $\geq 20 \mathrm{mg} / \mathrm{l}$ $(21.4 \%)$ was more than that in CRP level of $<20 \mathrm{mg} / \mathrm{l}(11 \%)$ but this finding was not statistically significant. This may be due to small sample size, as only five pregnant ladies who delivered pre-term had high CRP value, and only three cases had very high CRP level. Hvilsom et $\mathrm{al}^{23}$ in their prospective case-control study of cohort of 84 singleton preterm cases and 400 term controls, the authors reported that women with CRP concentrations $\geq 85^{\text {th }}$ percentile (i.e., $\geq 7.6 \mathrm{mg} / \mathrm{l}$ ) experienced a two-fold increased risk of preterm delivery (OR = 2.0, 95\% Cl: 1.2 - 3.5) compared with women who had lower CRP concentrations. However, the authors did not assess the risk of different sub-types of preterm delivery in relation to varying concentrations of CRP. The etiology of preterm delivery is undoubtedly multifactorial. It is this multi-factorial etiology that raised difficulties and differences in determining the effectiveness of various markers in the prediction of preterm delivery. ${ }^{30,31}$ Differences in study design, timing of blood collection, the underlying characteristics of the study population, and incomplete or no control for confounding may account for the variability in results across studies. For instance, investigators have noted that serum CRP concentrations measured in the third trimester (28 weeks gestation) is more strongly associated with preterm delivery, while concentrations measured in serum collected upon entry to prenatal care (first and early second trimesters) appear to be less strongly associated with preterm delivery, therefore we designed this study to measure CRP in the middle and late second trimester so we can add some data to those previous studies. The results of this study implicate serum-CRP in the mid second trimester, was not a possible risk marker of preterm delivery. This study had some limitations. First, a single measurement of serum CRP is not likely to provide a time-integrated measure of maternal inflammation status during the whole pregnancy. Second, the relatively small sample size of the study. Thus the relatively small number of cases who delivered preterm, especially those with very high CRP values, affected the results. 


\section{Conclusion}

Very high CRP levels exceeding the threshold $(\geq 20 \mathrm{mg} / \mathrm{l})$ might be associated with increased risk of preterm delivery independent of many other determinants of pre-term delivery. The association was apparent primarily for spontaneous preterm delivery but not significant. Future studies should evaluate whether changes in CRP levels over the course of pregnancy are predictive of at risk pregnancies for pre-term labor and to find the best time of pregnancy to do CRP screening in order to sort out the pregnancies at risk.

\section{Conflicts of interest}

The authors report no conflicts of interest.

\section{References}

1. American College of Obstetricians and Gynecologist. ACOG Practice Bulletin. Assessment of risk factors for preterm birth. Clinical management guidelines for obstetrician-gynecologists. Number 31, October 2001.

2. ACOG practice bulletin. Management of preterm labor.Number 43, May2003. Int J Gynaecol Obstet 2003; 82(1):127-35.

3. Tucker J, McGuire W. Epidemiology of preterm birth. BMJ 2004 ; 329(7467):675-78.

4. Murphy DJ. Epidemiology and environmental factors in preterm labor. Best Pract Res Clin Obstet Gynaecol 2007; 21(5):773-89.

5. Eden RD, Penka A, Britt DW, Landsberger EJ, Evans MI. Re-evaluating the role of the MFM specialist: lead, follow, or get out of the way. J Matern Fetal Neonatal Med 2005; 18(4):253-58.

6. Bennet P. Pretermlabor, Chapter 28, part 6 , in Keith Edmond (editor) Dewhurst's textbook of Obs \& Gyn., 8th edition 2012; p338-43

7.Vrachnis N, Vitoratos N, lliodromiti Z, Sifa K, Deligeoroglou E, Creatsas G. Intrauterine inflammation and preterm delivery. Ann NY Acad Sci 2010;1205:118-22.

8. Romero R, Mazor M. Infection and preterm labor. ClinObstetGynecol1988; 31: 553-84.

9. Luesly DM, Baker PN, Talor M. Late pregnancy/ intrapartum events. Preterm labor, Obstetrics and Gynecology, An evidence-based text for MRCOG second edition 2010;21:299-301.

10. McDonald HM, O'Loughlin JA, Jolley $P$, Vigneswaran R, McDonald PJ. Vaginal infection and preterm labor. Br J Obstet Gynecol 1991; 98 (5):427-35.

11. Romero R., Mazor M., Wu YK, Infection in the pathogenesis of preterm labor. Semin Perinatol 1988;12(4):262-79.
12. Dortbudak O, Eberhardt R, Ulm M, Persson GR. Periodontitis, a marker of risk in pregnancy for preterm birth. J Clin Periodontol 2005; 32(1): 45-52.

13. Offenbacher S., Lieff S., Boggess KA. Maternal periodontitis and prematurity. Part I: Obstetric outcome of prematurity and growth restriction. Ann Periodontol 2001; 6(1):164-74.

14. Thompson D., Pepys MB., Wood, SP. The physiological structure of human C-reactive protein and its complex with phosphocholine. Structure1999; 7(2): 169-77.

15. Castell JV.,Gomez-Lechon MJ., David M., Fabra R., Trullenque R., Heinrich PC. Acutephase response of human hepatocytes: regulation of acute-phase protein synthesis by interleukin-6. Hepatology1990; 12(5):1179-86.

16. Yap SH., Moshage HJ., Hazenberg BP. Tumor necrosis factor (TNF) inhibits interleukin (IL)-1 and/or IL-6 stimulated synthesis of C-reactive protein (CRP) and serum amyloid A (SAA) in primary cultures of human hepatocytes. Biochim Biophys Acta 1991; 1091(3):405-8.

17. Ford ES. Body mass index, diabetes, and C-reactive protein among U.S. adults. Diabetes Care,1999; 22(12):1971-7.

18. Pannacciulli N, Cantatore FP., Minenna A., Bellacicco M., Giorgino R., De Pergola G. $\mathrm{C}$-reactive protein is independently associated with total body fat, central fat, and insulin resistance in adult women. Int $\mathrm{J}$ Obes Relat Metab Disord 2001; 25(10):1416-20.

19. Mazor M, Kassis A., Horowitz S. Relationship between C-reactive protein levels and intraamniotic infection in women with preterm labor. J Reprod Med 1993; 38(10):799-803.

20. Potkul RK, Moawad AH., Ponto KL. The association of subclinical infection with preterm labor: the role of C-reactive protein. $\mathrm{Am} \mathrm{J}$ Obstet Gynecol 1985; 153(6):642-5.

21. Redman CW, Sacks GP., Sargent IL.. Preeclampsia: an excessive maternal inflammatory response to pregnancy. Am J Obstet Gynecol 1999; 180(2 Pt 1):499-506.

22. Yudkin JS., Stehouwer CD., Emeis JJ., Coppack SW. C-reactive protein in healthy subjects: associations with obesity, insulin resistance, and endothelial dysfunction: a potential role for cytokines originating from adipose tissue? Arterioscler Thromb Vasc Biol 1999; 19(4):972-8.

23. Hvilsom GB., Thorsen P., Jeune B, Bakketeig LS.. C-reactive protein: a serological marker for preterm delivery? Acta Obstet Gynecol Scand2002; 81(5):424-9.

24. Pitiphat W, Gillman MW,Joshipura KJ, Williams $\mathrm{PL}$, Douglass CW, Rich-Edwards JW. Plasma C-reactive protein in early pregnancy and preterm delivery. Am J Epidemiol 2005; 162(11):1108-13.

25. Vogel I, Grove J, Thorsen P., Moestrup SK., Uldbjerg N., Moller HJ. Preterm delivery predicted by soluble CD163 and CRP in women with 
symptoms of preterm delivery. B J Obstet Gynecol 2005; 112(6):737-42.

26. Romero R, Gomez R, Ghezzi F. A fetal systemic inflammatory response is followed by the spontaneous onset of preterm parturition. Am J Obstet Gynecol1998; 179:186-93

27. Ghezzi F., Franchi M., Raio L. Elevated amniotic fluid C-reactive protein at the time of genetic amniocentesis is a marker for preterm delivery. Am J Obstet Gynecol 2002; 186(2):268-73.

28. Borna S, Mirzaei F, Abdollahi A, Sarbiaei A.Predictive value of mid-trimester amniotic fluid high-sensitive C-reactive protein, ferritin, and lactate dehydrogenase for fetal growth restriction. I J Pathol 2009; (1):5-8.

29. Ozer KT, Kavak ZN, Gokaslan H, Elter K, Pekin T. Predictive power of maternal serum and amniotic fluid CRP and PAPP-A concentrations at the time of genetic amniocentesis for the preterm delivery 2005; 122(2):187-90.

30. Cark S., Belfort M., Dildy G., Herbst M., Meyers J., Hankins G. Maternal death in the 21st century: causes, prevention, and relationship to cesarean delivery. Am J Obstet Gyn 2008; 199(1): 36e1-36e5.

31. Lee Si., Romero R., Park CH., Jun J., Yoon B. The frequency and significance of intra amniotic inflammation in patients with cervical insufficiency. Am J ObstetGyn 2008; 198(6):633.el-633-e8. 